\title{
An Innovative Concept of Traceable Device for Monitoring Temperature of Temperature-Sensitive Healthcare Products
}

\author{
Pedro Martins de Oliveira ${ }^{1 *}$; Adriano Souza Leão ${ }^{1}$; Regina Maria Cunha Leite ${ }^{1}$; \\ Alfredo Ruben Corniali'; Marcos Lage Cajazeira Ramos ${ }^{1}$; Valter Estevão Beal ${ }^{1}$ \\ ${ }^{1}$ SENAICIMATEC University Center; Salvador, Bahia, Brazil
}

\begin{abstract}
This paper aims to present a concept of technology as a solution to monitor thermo-sensitive health products and contribute to preserving their integrity along the cold chain. This study is exploratory research with a case study involving a survey with health professionals and the use of tools for product development in order to find a solution to the problem of traceability and warnings about temperature deviations. From the information collected and the literature reviewed, it was possible to develop a concept of a product to meet the customer requirements. The results showed that thermo-sensitive health products lack traceability in the health network and that the concept presented contributes to solving this problem.

Keywords: Heat-Sensitive Products. Coldchain. IoT. Temperature Sensors.

Abbreviations: CCC (Cold Chain Central); WHO (World Health Organization); TSHP (TemperatureSensitive Healthcare Products), GPM (Good Manufacturing Practices); QFD (Quality Function Deployment); BUHS (Brazilian Unified Health System).
\end{abstract}

Monitoring the thermal stability of TemperatureSensitive HealthcareProducts(TSHP), temperature control with the adoption of Good Manufacturing Practices (GPM) over all stages of the logistic chain, comprises an essential challenge to the sector. The "cold chain" - technology and process - integrates multiples logistic and packaging stages of the products. Therefore, it is fundamental to evaluate, in an integrative manner, the equipment used to monitor, control, preserve, store and transport, and to maintain the temperature at each stage throughout the entire chain.

Healthcare products, such as vaccines, insulin, eye drops, biopharmaceuticals, laboratory reagents, blood derivatives, and other products, are sensitive to temperature deviations. Most of the TSHP must have their temperature monitored, and be kept at adequate conditions of storage

Received on 24 September 2019; revised 26 October 2019. Address for correspondence: Dr. Pedro Martins de Oliveira. Centro Universitário SENAI CIMATEC. Avenida Orlando Gomes, N. 1845 - Piatã Zip Code: 41650-010; Salvador, Bahia, Brazil. E-mail: pedromartins175@gmail.com. This study was selected from the V International Symposium of Innovation and Technology - SIINTEC (October 2019).

J Bioeng. Biotech. Appl. Health 2019;2(4):141-146

(C) 2019 by SENAI CIMATEC. All rights reserved. and transport to guarantee their integrity and efficiency according to the "Cold Chain Manual" of the National Immunization Program [1] and the "Cold Chain Manual" of the National Foundation of Health [2].

Two ranges of temperatures are primarely used and, therefore, at the Cold Chain Central (CCC), it must be stored and distributed with laboratory refrigerators $\left(+2^{\circ} \mathrm{C}\right.$ to $\left.+8^{\circ} \mathrm{C}\right)$ and freezers $\left(-25^{\circ} \mathrm{C}\right.$ to $\left.-15^{\circ} \mathrm{C}\right)$. Also, it is vital to keep a room for distribution, as well as a reception and inspection area.

It is crucial to guarantee the tracking of the TSHP across the entire cold chain in order to avoid damage caused by exposure to high temperatures [3] or freezing the products.

The WorldHealthOrganization(WHO)estimates that approximately $50 \%$ of the vaccines produced worldwide reach their destination with integrity compromised due to a break in the cold chain [4]. The temperature monitored in the Brazilian hospitals' sector is still conducted manually $[5,6]$. The commonly observed issues are: thermometers are often not calibrated; the measurement methods are not certified; the ice packs are not controlled, among several other problems. In many cases, domestic fridges and styrofoam boxes are used to 
maintain the temperature. The correct conservation and preservation of the TSHP must be a priority to all players involved, primarily because of thermal disturbances through the cold chain that may compromise product safety on its final use [1].

This article presents a concept to technology as a solution of monitoring the TSHP, which can contribute to preserving the integrity of TSHP along the cold chain. Exploratory research with a case study was conducted, comprising a survey with the cold chain professionals and the use of product development tools to find an innovative solution to the problem.

\section{The Brazilian Cold Chain of TSHP}

The stability of a healthcare product depends directly on the maintenance of the preset conditions over a certain period, preserving the physical integrity, power, purity, and efficiency [7]. One can state that once the TSHP is kept within the specified limits, at the end of the chain, the product will present the same characteristics as it had right after manufacturing, which means a guarantee of both therapeutic and diagnostic efficiency [8]. Figure 1 represents the logistic life cycle of the TSHP in the Brazilian scenario.

At the beginning of the cycle, the product is bundled at specific packages for each application, containing multiple protections for its physical integrity. It might include a primary package, as well as a secondary package (boxes with thermal insulation), not only for thermal protection but also for temperature preservation. Therefore, the TSHP can be delivered by the producer to the GMP under all certification criteria.

Thefirst stop of the TSHPjourney is a distribution center. During transportation, the carrier must protect the product against breakage, tampering, and theft, as well as ensure that temperature conditions would be maintained within the preset thresholds. The temperature maintenance has to consider the environmental conditions to which the product is exposed. Thus, energy provision is often needed.

After the reception of the product at the distribution center, the temperature is measured manually; and the product will be sent to the next destination with another transporter. The next step happens in drug storages inside hospitals, clinics, or vaccination centers. The products are received and stored in lab refrigerators and freezers to preserve the TSHP, where they manually measure temperature, which is controlled daily. These devices have precise temperature adjustment and several malfunction alarms. It is important to note that no cold chain manual has a prominent warning about household equipment, which is not recommended for TSHP storage, nor allowed to use the mini-bar fridge [1]. Even so, household equipment is widely used.

Due to the lack of control mechanisms, products are exposed due to power outage, shutdown, inadvertent door opening, and others that can undesirably change their temperature conditions. In those facilities, the products must remain in proper conditions as long as needed until their use is determined, e.g., in a patient's treatment or procedure.

During internal handling and transport, temperature control is also performed manually until the product is used, but no mechanism allows its traceability or data integration from end-to-end along the cold chain. Thus, there is no guarantee that the product has not lost the proper temperature condition by either raising or lowering the temperature outside its limits. These deviations may cause product loss.

Figure 1. Cold chain life cycle.

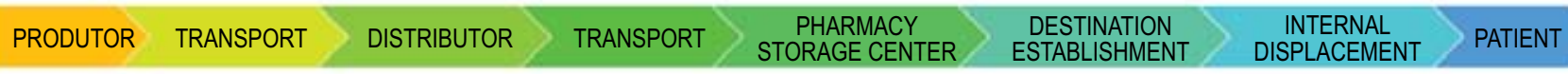


There are two key strategies to ensure integrity throughout the process: one is the "equipment validation" upon assessment and reliability. Other is the "processes qualification" that records, controls, and audits the procedures performed. Thus, traceability data can be obtained to monitor cold chain operations [1].

In Brazil, the lack of vehicles and highways in proper condition can affect logistics and, as a consequence, the quality of products transported, as it is a continental country and the most used mean of transportation is road type, reaching 59\% [7]. The lack of adequate equipment for product storage and temperature control methods can also be as weak points.

\section{Materials and Methods}

The research strategy chosen was the case study due to the need to understand the situation of the health sector and propose a conceptual solution. The study was developed in two steps. Firstly, an understanding of the situation, secondly, the study of the solution (Figure 2).

Figure 2. Research design.
The first stage consisted of identifying and understanding the problem. Asurvey with managers and other professionals with relevant functions in the public and private health network was conducted aiming to diagnose the transportation and storage situation of products in the TSHP network in Brazil. Questionnaires were sent to 50 professionals, and 18 replies were received. A literature review was also carried out in order to learn the available technologies, competitors, and patents. To understand the appropriate steps for the development of a product, we studied the life cycle of a TSHP. Thus, it was possible to identify customer needs.

In the second step, project requirements were translated from customer needs. A QFD Matrix was built to rank the project requirements, ordered by their importance to the customer. Then, a functional synthesis was made to identify the functions that the product should perform, which yielded a basis for the morphological Matrix. Then, the concepts were generated, and a winning concept was selected after a ranking analysis. This concept was indicated in this study as a solution.
Understanding the Situation

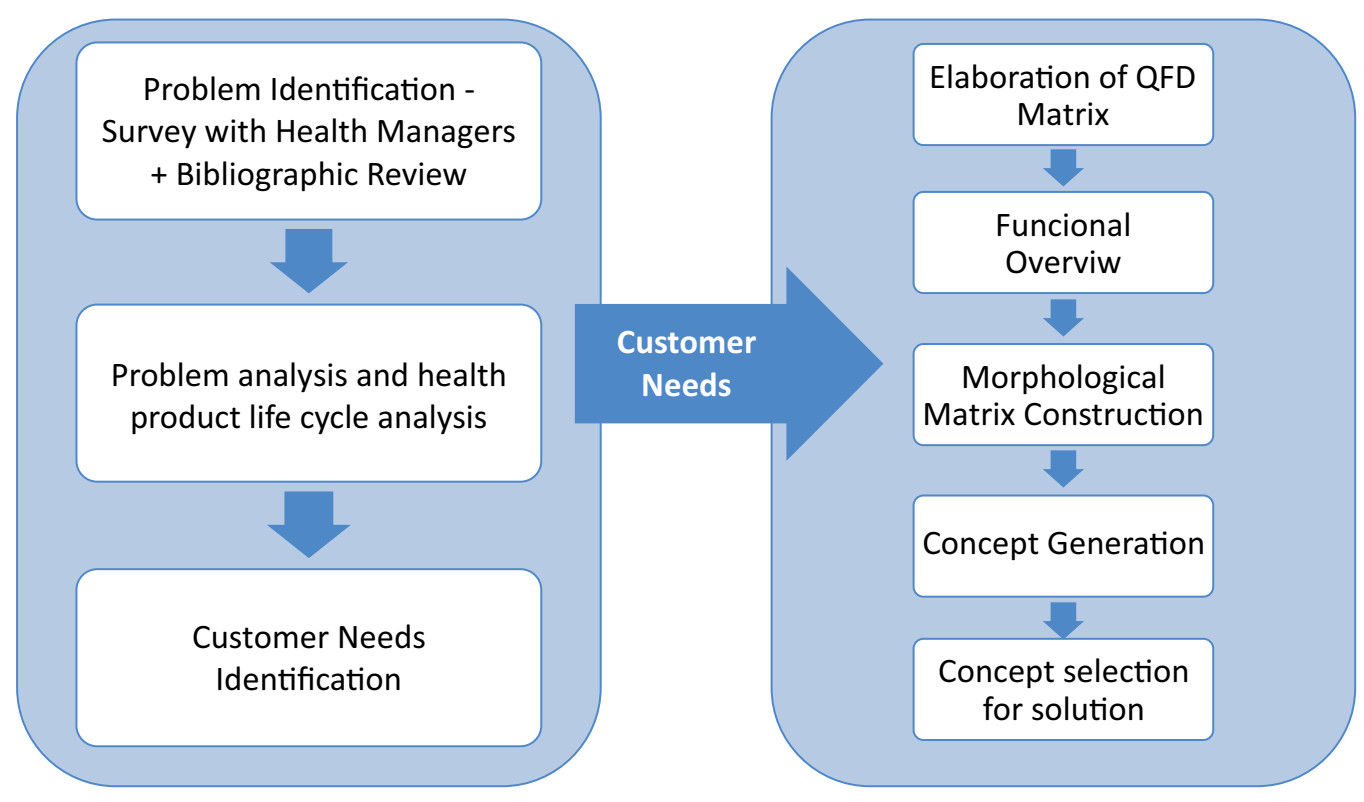

The Solution Study 
Diagnosis of the Situation in the Health Network

Key customers throughout the lifecycle were identified to gather information about their needs, whereas their assessments would be representative of the overall process. BUHS professionals, hospitals, clinical analysis laboratories, pharmacies, and carriers were consulted. The first questionnaire with 14 questions was prepared using the Google Forms tool, seeking to collect data as fully as possible, avoiding invasiveness as well as biasing of the questions.

Then, once the customer needs were identified, the respondents were asked to indicate aspects not mentioned before but deemed relevant. After that, they were asked to sign values to the needs according to their activity.

\section{The Concept Generation Process}

In total, 17 needs were identified. Then, a QFD Matrix was developed, also known as a 'Quality House', which is a method that transforms customer needs into project requirements [11]. These must be measurable in order to be transformed into useful product characteristics, so-called concepts), by the engineering perspective. Then, the requirements were listed and sorted by importance to the customer. The main requirements were: (1) reliability, (2) a low number of equipment failures per time of use, (3) minor errors in temperature measurement, (4) optimal amount of information provided, (5) low reject rate of TSHP and (6) low production cost.

The essential requirement is the reliability of the patient or healthcare professional. The following five needs show the importance of screening for healthcare professionals. End-to-end tracking of a product is a crucial procedure to ensure health care quality. Moreover, the low-cost of production appear to implement this type of innovation feasible.

Then, a functional synthesis was performed, which unfolded the function of tracking health products into five sub-functions: (1) receipt, (2) transportation, (3) storage, (4) local handling and transport, and (5) application / patient use.
A morphological matrix was constructed over a detailed study of each subfunction. A morphological matrix is a tool that systematically allows studying possible combinations between the components of a product [12]. It consists of a table in which the first vertical column contains the characteristics of the functions and subfunctions, and the horizontal lines contain the alternatives for each subfunction [12]. To aid the idea generation process for an ideal solution, the TRIZ Matrix was used, a method created by the Russian Genrich Altshuller in the mid-1940s, which uses 40 inventive principles to resolve technical contradictions [13].

From the analysis of the Morphological Matrix, six different concepts were obtained. Then, they were assessed seeking an ideal solution, aided by the Pass-Fail Evaluation method [12] in two rounds. In the first round, the six concepts were assessed and qualified. In the second round, the three concepts with the highest scores from the first round were used, resulting in a winning concept.

\section{The Winning Concept}

From the morphological matrix, the client's need could be understood and translated into different concepts that meet this demand. After assessing these concepts, it was possible to select a winning concept (Figure 3).

The proposed solution stands out for its innovative concept, where it tracks the TSHP to the end-user, and a system allows storing administrative information of the monitored product (Product, Lot No., Expiration Date, Invoice No.) as well as location, from the system reference antennae. It meets the demands obtained by the analysis of customer needs and has the potential for success against competitors and similar products found in the market.

Amongst the advantages that can be highlighted, one is the verification of product integrity through the dynamic reading of the data tracked and stored in the cloud/server logistics management system. The Ultra Narrow Band system, with low data transmission at low throughput, is responsible for 
Figure 3. The selected concept and characteristics.

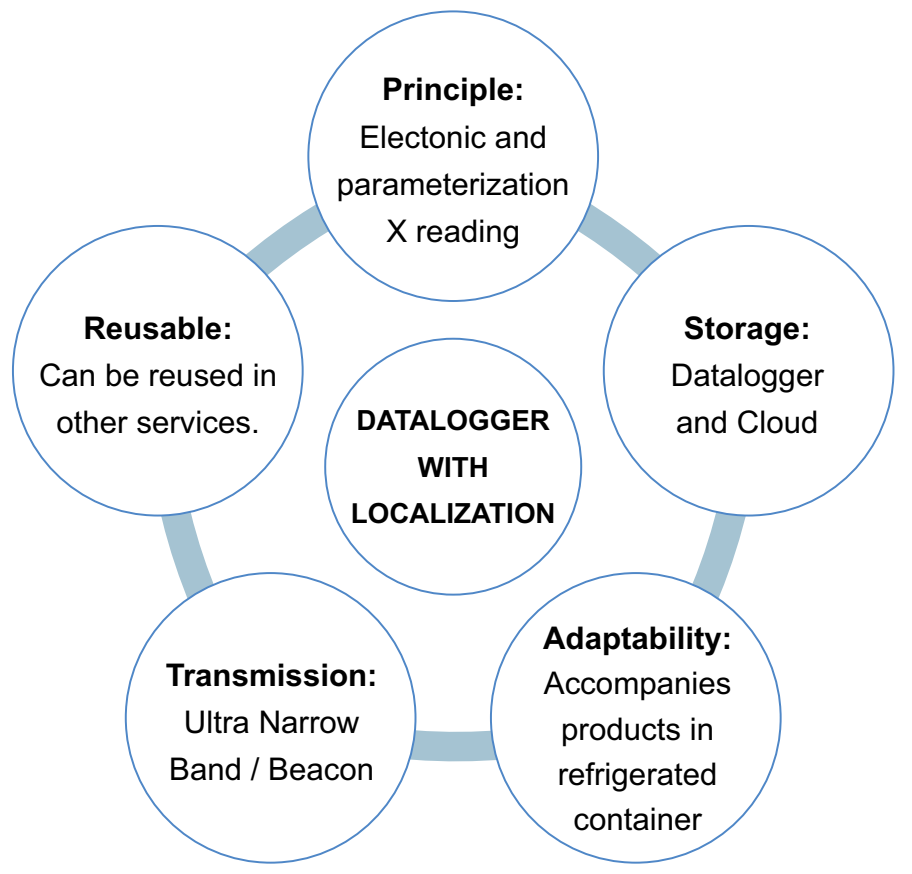

\author{
Features \\ - Electonic principle - Termistor; \\ - Parameterization x Reading; \\ - Accompanied in refigerated container; \\ - It has motion sensor, internal location \\ (<10m bubble); \\ - Stores information in Datalogger and \\ Cloud (real time remote access); \\ - Performs data transmission by Ultra \\ Narrow Band / Beacon; \\ - It is reusable, has 130bpi e-ink, LED, BLE \\ and Bidirectional Screen; \\ - It has 5 years battery, Bluetooth 5.0 with \\ directional location with a range between \\ 30 and 50 meters, carries all the \\ information and updates the distance.
}

system communication, yet robust, and has a low interference rate.

\section{Final Considerations}

The medical industry manages high-cost and value-added products. Such products, if mismanaged, can result in severe financial and moral damage to institutions. The market analysis of products and services that depend on the cold chain allowed an understanding of the temperature control needs of TSHPs as well as working on the weaknesses that have become strengths of the concept presented.

Furthermore, the innovation industry is striding towards integrated data and information systems, where IoT appears as one of the main features of the new technological age. The winning concept can integrate the various actors along the cold chain (manufacturer, carrier, distributor, end consumer), and meeting the demands of traceability, both temperature and product location, a function that few competitors can achieve. This proposition could perform from end-to-end, integrating the logistics operation of these products and enabling the viewing of administrative data with no need to open the packaging, which represents a new application for the market.

\section{References}

1. Departamento de Vigilância Epidemiológica. Programa Nacional de Imunizações (PNI): 40 anos. Secretaria de Vigilância em Saúde. Ministério da Saúde. 2013.

2. Rocha CMV et al. Manual de rede de frio 3. Ed Brasília: Ministério da Saúde: Fundação Nacional de Saúde. 2001.

3. Ruiz-Garcia L, Lunadei L. Monitoring cold chain logistics by means of RFID. Sustainable Radio Frequency Identification Solutions. 2010;2:37-50.

4. Fiocruz. Os desafios da cadeia de frio na indústria farmacêutica. Bio-Manguinhos/FIOCRUZ. 2015. [Online] Available: https://www.bio.fiocruz.br/index. $\mathrm{php} /$ noticias/991-os-desafios-da-cadeia-de-frio-naindustria-farmaceutica. Accessed on Feb.12,2019.

5. Ávila A. Identificação por radiofrequência: tecnologia inteligente, hospital eficiente, qualidade e segurança para o paciente. Thesis. Instituto de Comunicação e Informação Científica e Tecnológica em Saúde, Fundação Oswaldo Cruz / Grupo Hospitalar Conceição. Rio Grande do Sul, 2012.

6. Alves ETA et al. Estudo de caso: sistema para monitoramento de temperatura e umidade em farmácias e almoxarifados. In: Congresso Brasileiro de Engenharia Biomédica. 2014:1208-1211. 
7. Carvalho JS, Macedo SHM. Logística Farmacêutica Geral: Da Teoria à Prática. São Paulo. Contento. 2012.

8. Silva KER, Alves LDS, Soares MFR, Passos RCS, Faria AR, Rolimneto PJ. Modelos de avaliação da estabilidade de fármacos e medicamentos para a indústria farmacêutica. Rev. Ciênc. Farm. Básica Apl. 2009.

9. Kang $\mathrm{S}$ et al. Laboratory environment monitoring: Implementation experience and field study in a tertiary general hospital. Healthcare Informatics Research. 2018;24(4):371-375.
10. Roduit B et al. Continuous monitoring of shelf lives of materials by application of data loggers with implemented kinetic parameters. Molecules. 2019;24(12):2217.

11. Bolar AA, Tesfamariam S, Sadiq R. Framework for prioritizing infrastructure user expectations using Quality Function Deployment. International Journal of Sustainable Built Environment. 2017;6(1):16-29.

12. Amaral DC et al. Gestão de desenvolvimento de produtos. Editora Saraiva. 2017.

13. Altshuller G. 40 principles: TRIZ keys to innovation. Technical Innovation Center, Inc. 2002. 